\title{
Temporal Change in Human Nicotinic Acetylcholine Receptor After Smoking Cessation: 5IA SPECT Study
}

\author{
Marcelo Mamede ${ }^{1}$, Koichi Ishizu${ }^{1}$, Masashi Ueda², Takahiro Mukai ${ }^{1}$, Yasuhiko Iida ${ }^{2}$, Hidekazu Kawashima ${ }^{2}$, \\ Hidenao Fukuyama ${ }^{3}$, Kaori Togashi ${ }^{1}$, and Hideo Saji ${ }^{2}$ \\ ${ }^{1}$ Department of Diagnostic Imaging and Nuclear Medicine, Graduate School of Medicine, Kyoto University, Kyoto, Japan; ${ }^{2}$ Department \\ of Patho-Functional Bioanalysis, Graduate School of Pharmaceutical Science, Kyoto University, Kyoto, Japan; and ${ }^{3}$ Brain Function \\ Imaging Division, Human Brain Research Center, Graduate School of Medicine, Kyoto University, Kyoto, Japan
}

Nicotinic acetylcholine receptors (nAChRs) are of great interest because they are implicated in various brain functions. They also are thought to play an important role in nicotine addiction of smokers. Chronic (-)-nicotine, a nAChR agonist, treatment in mice and rats elicits a dose-dependent increase in nAChRs in the brain. Upregulation of nAChRs in postmortem human brains of smokers has also been reported. However, changes in nAChRs after cigarette smoking cessation in humans are poorly understood. The aim of this study was to detect the dynamic changes of $\mathrm{nAChRs}$ after smoking and smoking cessation in the brains of living subjects. Methods: We performed 5-123|iodo-A-85380 ( ${ }^{123}$ I-5IA) SPECT on nonsmokers and smokers $(n=16)$ who had quit smoking for $4 \mathrm{~h}, 10 \mathrm{~d}$, and $21 \mathrm{~d}$ and calculated and compared distribution volumes $(V t)$ of ${ }^{123}|-5| A$. Results: The binding potential of $n A C h R s$ (Vt of $\left.{ }^{123} \mid-5 I A\right)$ in the brains of smokers decreased by $33.5 \% \pm 10.5 \%$ after $4 \mathrm{~h}$ of smoking cessation, increased by $25.7 \% \pm 9.2 \%$ after $10 \mathrm{~d}$ of smoking cessation, and decreased to the level of nonsmokers after $21 \mathrm{~d}$ of smoking cessation. Conclusion: Because the upregulation of the $\mathrm{nAChRs}$ of the smokers after chronic exposure of the nicotine was downregulated to the nonsmokers' level by around $21 \mathrm{~d}$ after smoking cessation, the upregulation is a temporary effect. The decrease in nicotinic receptors to nonsmoker levels may be the breaking point during the nicotine withdrawal period.

Key Words: ${ }^{123}$ I-5IA; SPECT; nicotinic acetylcholine receptors; human brain; smoking withdrawal; quantitative measurement

J Nucl Med 2007; 48:1829-1835

DOI: 10.2967/jnumed.107.043471

$\mathbf{N}$ Picotinic acetylcholine receptors (nAChRs) are a family of ligand-gated ion channels that regulate neurotransmission in the central and peripheral nervous systems. These receptors are of great interest because they are implicated

Received May 9, 2007; revision accepted Jul. 30, 2007

For correspondence or reprints contact: Koichi Ishizu, MD, PhD, Department of Diagnostic Imaging and Nuclear Medicine, Graduate School of Medicine, Kyoto University, Sakyo, 606-8507, Kyoto, Japan.

E-mail: ishizu@kuhp.kyoto-u.ac.jp

COPYRIGHT @ 2007 by the Society of Nuclear Medicine, Inc. in various brain functions, including cognition and memory $(1,2)$ and in nicotine-induced neuroprotective $(3)$ and analgesic effects (4). In addition, these receptors are thought to play an important role in nicotine addiction (5).

Chronic treatment with agonists for most neurotransmitter receptor systems results in a decrease in receptor number. However, it has been demonstrated that chronic treatment of mice (6) and rats (7) with (-)-nicotine, an nAChR agonist, elicits a dose-dependent increase in nAChRs. This upregulation is not permanent, returning to control levels within $7-10 \mathrm{~d}$ in mice $(6)$ and $15-20 \mathrm{~d}$ in rats $(8,9)$ after cessation of (-)-nicotine treatment. Previous efforts to demonstrate nAChR upregulation in the human brain have also been reported primarily in in vitro binding assays $(10,11)$. Kassiou et al. reported the upregulation of nAChRs with chronic (-)nicotine treatment in the brain of a live baboon (12). More recently, Staley et al. described the upregulation of nAChRs in human brains after early abstinence of tobacco smoking using 5- ${ }^{123}$ I-iodo-A-85380 ( $\left.{ }^{123} \mathrm{I}-5 \mathrm{IA}\right)$ and SPECT images (13). However, changes in nAChRs in humans after cessation of smoking are poorly understood. Breese et al. studied the levels of ${ }^{3} \mathrm{H}$-nicotine binding in humans postmortem for changes in nicotinic receptor levels and reported that the nAChR levels in smokers who had stopped smoking at least 2 mo before their death were similar to those in nonsmokers (14); the effects of shorter-term smoking cessation are unknown.

${ }^{123} \mathrm{I}-5 \mathrm{IA}$ is a nAChR imaging probe that has extremely high selectivity and specificity for the $\alpha 4 \beta 2$ subunit of $\mathrm{nAChRs}$ in rodent (inhibition constant $=0.37 \mathrm{nM})(15)$ and primate brain in vivo $(16)$, with relatively low acute toxicity (effective dose equivalent $=30 \mu \mathrm{Sv} / \mathrm{MBq})(17,18)$. Moreover, we have developed the methodology for the quantification of nAChRs in human brain using ${ }^{123}$ I-5IA and SPECT (19).

The aim of the present study was to detect the dynamic changes of nAChRs in living human brain after smoking and smoking cessation. We performed ${ }^{123}$ I-5IA SPECT on nonsmokers and smokers who had quit smoking for $4 \mathrm{~h}, 10 \mathrm{~d}$, and 
$21 \mathrm{~d}$ and compared the distribution volumes $(V t)$ of ${ }^{123}$ I-5IA of each group and with nonsmokers. To our knowledge, this is the first in vivo imaging study of nAChR upregulation and recovery in response to short-term smoking cessation in living subjects.

\section{MATERIALS AND METHODS}

\section{Volunteers}

Six male nonsmokers $(23 \pm 6 \mathrm{y})$ and 10 healthy male smokers $(28 \pm 4$ y) were included in this study. Five smokers in the 4-h group were also included in either the 10-d or the 21-d group. In total, $21{ }^{123}$ I-5IA SPECT studies were acquired (Table 1). None of the subjects had a history of neurologic or psychiatric illness or the use of psychotropic or sleep-inducing drugs. The nonsmokers had no history of smoking tobacco.

For the smoking withdrawal studies, the smokers were divided in 3 groups: 5 subjects (age, $28 \pm 4$ y) for 4-h withdrawal, 5 subjects (age, $27 \pm 6$ y) for 10-d withdrawal, and 5 subjects (age, $28 \pm 3$ y) for $21 \mathrm{~d}$ of smoking withdrawal. The 4 groups were age-matched.

All subjects gave written informed consent to participate in this study in compliance with the regulations of the Joint Committee on Clinical Investigation of the Kyoto University Hospital.

\section{Radiolabeling}

Radiolabeling of the ${ }^{123}$ I-5IA followed the methods we reported previously (19). To a sodium ${ }^{123}$ I-iodide solution $(1,110 \mathrm{MBq})$ (Nihon Medi-Physics), $100 \mu \mathrm{g}$ of $(S)$-5-(tri- $n$-butylstannyl)-3-([1- $t$ butoxycarbonyl-2(S)-azetidinyl]methoxy)pyridine, $1.5 \%$ acetic acid, $3 \mathrm{~mol} / \mathrm{L} \mathrm{HCl}$, and $5 \% \mathrm{H}_{2} \mathrm{O}_{2}$ solution were added, and the mixture was stirred at $75^{\circ} \mathrm{C}$ for $15 \mathrm{~min}$. Concentrated $\mathrm{HCl}$ was then added, and the resulting solution was stirred for another $10 \mathrm{~min}$ at $75^{\circ} \mathrm{C}$. The mixture was made basic with $\mathrm{NaOH}$ and extracted with ethyl acetate, and the organic layer was evaporated. The residue was purified by reverse-phase high-performance liquid chromatography ([HPLC] Cosmosil 5C18-AR-300, $10 \times 250 \mathrm{~mm}$; Nacalai Tesque; $10 \mathrm{mmol} / \mathrm{L}$ ammonium acetate/methanol/triethylamine $=$ 752:750:2; $1.5 \mathrm{~mL} / \mathrm{min}$; retention time for 5IA was $40 \mathrm{~min}$ ). After evaporation of the HPLC eluent, the residue was dissolved in $0.9 \%$ saline and filtered through a $0.2-\mu \mathrm{m}$ filter into a sterile vial. Radiochemical purity was $>98 \%$, and radiochemical yields were $\sim 42 \%$. The specific activity determined from the ultraviolet absorbance at $254 \mathrm{~nm}$ was $>169 \mathrm{GBq} / \mu \mathrm{mol}$ (the detection limit for this method).

\section{SPECT}

All subjects underwent a set of 5 SPECT dynamic scans (a 120min scan, followed by 4 sets of 20-min scans). All SPECT dynamic scans were acquired with a triple-head rotating $\gamma$-camera system

TABLE 1

Study Groups

\begin{tabular}{llll}
\hline & \multicolumn{3}{c}{ Smokers: period of smoking cessation } \\
\cline { 2 - 4 } Nonsmokers & \multicolumn{1}{c}{$4 \mathrm{~h}$} & 10 d & 21 d \\
\hline Subject 1 & Subject 7 & Subject 7 & Subject 9 \\
Subject 2 & Subject 8 & Subject 8 & Subject 10 \\
Subject 3 & Subject 9 & Subject 12 & Subject 11 \\
Subject 4 & Subject 10 & Subject 13 & Subject 15 \\
Subject 5 & Subject 11 & Subject 14 & Subject 16 \\
Subject 6 & & & \\
\hline
\end{tabular}

(PRISM 3000; Picker International) equipped with low-energy, high-resolution, fanbeam collimators. Data acquisition and image reconstruction were performed as in our previous study (19). The data acquisition was alternately performed over 120 min after intravenous injection of ${ }^{123}$ I-5IA, followed by 4 sets of 20-min scans (at 3, 4, 5, and $6 \mathrm{~h}$ after the injection). SPECT images were reconstructed using a filtered backprojection algorithm with a ramp filter. Attenuation correction was performed using ellipses outer line approximation and Chang's method (coefficient of $0.06 / \mathrm{cm}$ ), which assumes that the attenuation process is homogeneous throughout the brain and can be described by an exponential function. Scatter correction was not applied.

A dose of $\sim 150 \mathrm{MBq}$ of ${ }^{123}$ I-5IA was administered intravenously over a period of $1 \mathrm{~min}$ at a constant rate with an infusion pump, and the SPECT scan was started at the same time as the injection. Arterial blood sampling and metabolite correction were also performed to estimate the arterial input function of the ${ }^{123}$ I-5IA for each volunteer by the same method as that used in our earlier study (19).

\section{Arterial Input Function}

Twenty-five arterial blood samples were obtained at the same time points as described previously (19). From each sample, $100 \mu \mathrm{L}$ of plasma were removed and the radioactivity was measured in an automatic well-type $\gamma$-counter (Cobra 2; Packard Instruments). Sixteen samples were analyzed by thin-layer chromatography (TLC) (10\% ammonium acetate and methanol [1:1], LK6DF Silica Gel, $60 \AA$; Whatman) for metabolite determination $\left(\mathrm{R}_{\mathrm{f}}=0.55\right.$ for ${ }^{123}$ I-5IA) (19). The measured unmetabolized fractions were fitted with a dual exponential curve, and the input function was calculated as all plasma sample counts were corrected for metabolites using the fitted curve.

\section{Data Analysis}

Reconstructed SPECT images were automatically coregistered using a coregistration algorism of statistical parametric mapping, SPM99 (Welcome Department of Cognitive Neurology, London, U.K.), to minimize positional error caused by head movement during the scans. Multiple circular regions of interest (ROIs) (21 pixels per circle) were manually drawn in each brain region (basal ganglia, thalamus, brain stem, cerebellum, frontal, parietal, temporal, and occipital cortices) on both sides. ROI data were further decay-corrected. SPECT data were calibrated to the well counter used to measure the injected activity. Time-activity curves were generated from the ROIs and the dynamic image datasets.

Kinetic analysis of the ${ }^{123}$ I-5IA was performed using a 2compartment model including $K_{1}$ and $k_{2}$ rate constants and a curvefitting method following our previous study (19). $V t$ values of the ${ }^{123}$ I-5IA were calculated and used as a quantitative index correlated with the regional binding potential of the nAChRs. The $V t$ values were further evaluated in terms of interval change after the smoking withdrawal.

\section{Statistical Analysis}

All data are expressed as the mean $\pm \mathrm{SD}$. The $V t$ values obtained from the different regions in the brain were analyzed by 1-way ANOVA with the Bonferroni protected least significant difference test. The interval changes of the ${ }^{123}$ I-5IA $V t$ were analyzed between the 3 phases after the smoking withdrawal using the Tukey-Kramer multiple comparison test. All tests were 2-sided, and probability values of $P<0.05$ were considered significant. 


\section{RESULTS}

As in our previous study (19), the characteristics of the arterial input functions for all volunteers (nonsmokers and smokers) were similar. The peak plasma activity occurred between 70 and $80 \mathrm{~s}$ after injection in all subjects and decreased rapidly to $6.5 \%-9.0 \%$ of the peak level in $10 \mathrm{~min}$. Analysis of the unmetabolized compound by TLC demonstrated a high parent fraction of ${ }^{123}$ I-5IA in the plasma $(87.7 \% \pm 6.3 \%)$ in the first minute. ${ }^{123}$ I-5IA was rapidly metabolized, and the unchanged fraction represented $50.9 \% \pm 8.8 \%$ and $32.4 \% \pm 12.6 \%$ of total plasma activity at 20 and $60 \mathrm{~min}$, respectively.

Figure 1 shows the representative standardized time-activity curve of ${ }^{123}$ I-5IA in the frontal cortex. The concentrations of radioactivity were slightly higher in the nonsmokers and in the 4-h smoking-cessation group followed by the 10-d and 21-d smoking-cessation groups. The peaks of radioactivity occurred $\sim 50$ min after injection of ${ }^{123}$ I-5IA for nonsmokers and for the 4-h and 21-d smoking-cessation groups, whereas it was at $\sim 70 \mathrm{~min}$ for the 10-d smoking-cessation group. A differential dissociation of ${ }^{123}$ I-5IA from the binding sites was noted in the brain. The 4-h smoking-cessation group showed a faster dissociation compared with that of the nonsmokers. However, the 10-d and 21-d smoking-cessation groups showed a slower dissociation than that of the nonsmokers (more pronounced in the 21-d group). These findings reflected a temporal change of the nAChRs in the human brain.

Packs per day and pack years of cigarette smoking before cessation were similar for the different groups of smokers (Table 2). Only 2 subjects (subjects 7 and 11) had detectable amounts of nicotine in their plasma after 4-h smoking cessation (Table 2).

To validate the $V t$ values of the nonsmokers as a baseline group, we compared ( $t$ test) our current data (nonsmokers) with our published data (19). No significant difference was observed between these groups. Similar findings were also seen for $K_{1}$ and $k_{2}$. Therefore, we used the $V t$ values from nonsmokers as a reference for further comparisons with groups of smokers at several smoking-cessation intervals.

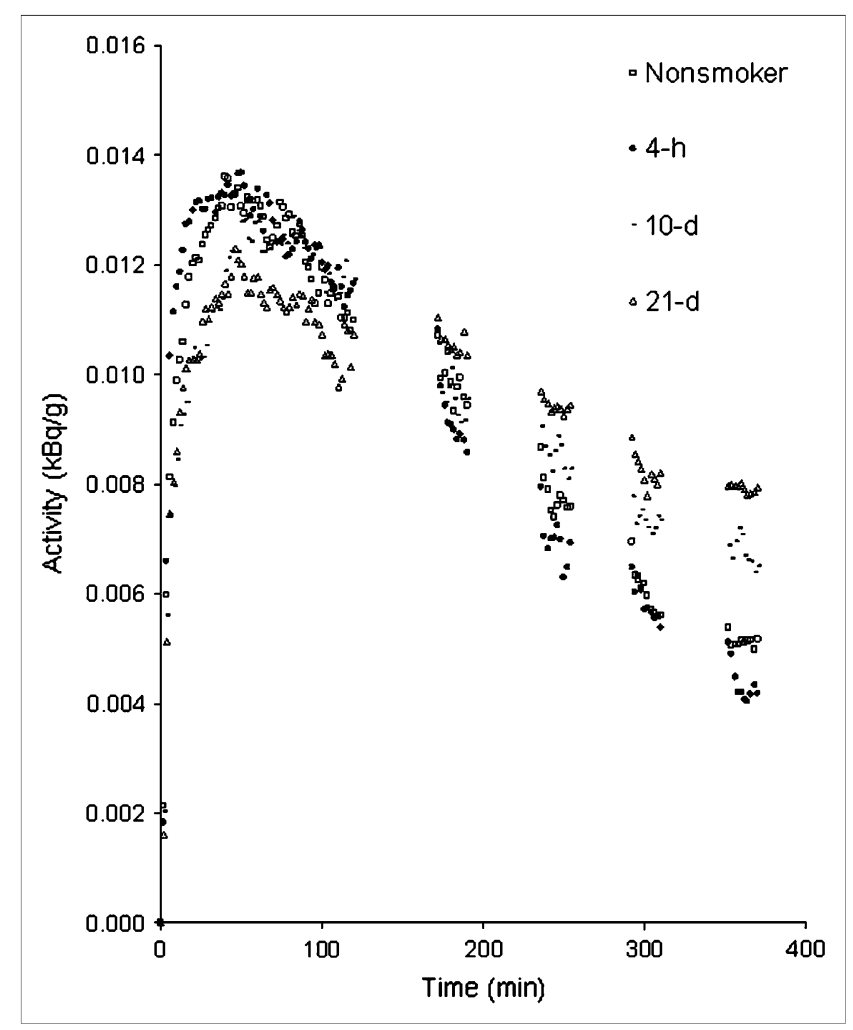

FIGURE 1. Representative standardized time-activity curves of ${ }^{123} \mathrm{I}-5 \mathrm{IA}$ in frontal cortex from a nonsmoker and smokers.

Table 3 describes the $V t$ values of different groups of volunteers (nonsmokers and smokers). There was a significant difference among those groups (ANOVA; $P<0.001$ ). Individualized comparisons between 2 groups of volunteers were also performed. After $4 \mathrm{~h}$ of smoking cessation, the $V t$ values in all brain regions decreased significantly compared with those of the nonsmoker group $(P<0.05$, except for frontal, parietal, and occipital cortices). On the other hand, after $10 \mathrm{~d}$ of smoking cessation, the $V t$ values were significantly higher than those of nonsmokers $(P<0.05$, except for basal ganglia and thalamus). Then, after $21 \mathrm{~d}$ of smoking cessation, the $V t$ values decreased significantly compared

TABLE 2

Characteristics of Volunteers and Plasma Concentration of Nicotine and Cotinine

\begin{tabular}{|c|c|c|c|c|c|}
\hline \multirow[b]{2}{*}{ Group } & \multirow[b]{2}{*}{ Age $(y \pm S D)$} & \multirow[b]{2}{*}{ Packs/d } & \multirow[b]{2}{*}{ Pack years } & \multicolumn{2}{|c|}{ Plasma concentration ( $\mathrm{ng} / \mathrm{mL})$} \\
\hline & & & & Nicotine & Cotinine \\
\hline Nonsmokers & $24 \pm 6$ & - & - & ND & ND \\
\hline \multicolumn{6}{|l|}{ Smokers } \\
\hline 4-h withdrawal & $28 \pm 4$ & $0.8 \pm 0.3$ & $6.1 \pm 4.3$ & $7.6,8.9^{*}$ & $282 \pm 189$ \\
\hline 10-d withdrawal & $27 \pm 6$ & $0.8 \pm 0.2$ & $6.3 \pm 3.9$ & ND & ND \\
\hline 21-d withdrawal & $28 \pm 3$ & $0.8 \pm 0.3$ & $6.3 \pm 4.5$ & ND & ND \\
\hline
\end{tabular}

${ }^{\star}$ Results from only 2 subjects (3 other subjects had nondetectable values).

Packs/d = number of packs smoked per day; Pack years = number of packs per day while smoking multiplied by number of years smoked; ND = not detected (detection limits for nicotine and cotinine were 5.0 and $100 \mathrm{ng} / \mathrm{mL}$, respectively).

Values are expressed in mean $\pm \mathrm{SD}$. 
TABLE 3

123I-5IA $V_{t}$ Estimates for 2-Compartment, 2-Parameter Model for Various Brain Regions from Nonsmokers and Smokers After Withdrawal of Cigarette Smoking

\begin{tabular}{|c|c|c|c|c|c|c|c|c|}
\hline Subject & Frontal & Parietal & Temporal & Occipital & $B G$ & Thalamus & BS & Cerebellum \\
\hline \multicolumn{9}{|c|}{ Nonsmokers } \\
\hline 1 & 14.3 & 13.2 & 13.2 & 11.2 & 15.8 & 30.1 & 22.9 & 15.6 \\
\hline 2 & 20.3 & 18.9 & 19.7 & 16.2 & 24.2 & 43.2 & 35.5 & 20.5 \\
\hline 3 & 14.1 & 13.0 & 13.8 & 11.2 & 16.0 & 28.4 & 22.3 & 14.9 \\
\hline 4 & 14.4 & 14.4 & 14.6 & 11.7 & 17.2 & 31.1 & 25.3 & 18.4 \\
\hline 5 & 11.3 & 10.7 & 10.7 & 9.5 & 12.9 & 19.3 & 17.7 & 14.4 \\
\hline 6 & 13.2 & 12.2 & 12.2 & 11.1 & 13.5 & 20.9 & 18.7 & 13.7 \\
\hline Mean & 14.6 & 13.7 & 14.0 & 11.8 & 16.6 & 28.8 & 23.7 & 16.3 \\
\hline SD & 3.0 & 2.8 & 3.1 & 2.3 & 4.0 & 8.6 & 6.4 & 2.7 \\
\hline \multicolumn{9}{|l|}{ Smokers } \\
\hline \multicolumn{9}{|c|}{ 4-h withdrawal } \\
\hline 7 & 6.1 & 6.3 & 6.4 & 5.9 & 6.5 & 7.0 & 7.0 & 5.9 \\
\hline 8 & 12.6 & 13.0 & 12.2 & 11.4 & 12.8 & 16.1 & 14.0 & 11.3 \\
\hline 9 & 14.9 & 14.0 & 13.7 & 12.5 & 15.0 & 21.3 & 19.4 & 14.4 \\
\hline 10 & 8.7 & 8.4 & 8.6 & 7.6 & 10.0 & 13.5 & 12.2 & 8.8 \\
\hline 11 & 10.2 & 10.4 & 10.2 & 9.0 & 11.2 & 12.9 & 12.3 & 10.0 \\
\hline Mean & 10.5 & 10.4 & 10.2 & 9.3 & 11.1 & 14.1 & 13.0 & 10.1 \\
\hline SD & 3.4 & 3.2 & 2.9 & 2.7 & 3.2 & 5.2 & 4.4 & 3.1 \\
\hline \multicolumn{9}{|c|}{ 10-d withdrawal } \\
\hline 7 & 19.7 & 19.3 & 19.2 & 17.5 & 21.0 & 31.1 & 29.4 & 20.9 \\
\hline 8 & 19.1 & 18.7 & 17.4 & 16.4 & 19.4 & 28.7 & 25.3 & 20.7 \\
\hline 12 & 18.0 & 17.6 & 17.4 & 16.1 & 20.2 & 28.9 & 30.3 & 22.4 \\
\hline 13 & 16.1 & 16.2 & 16.4 & 15.2 & 18.7 & 28.9 & 29.3 & 20.8 \\
\hline 14 & 19.2 & 18.1 & 17.8 & 15.8 & 21.5 & 36.5 & 32.8 & 23.9 \\
\hline Mean & 18.4 & 18.0 & 17.6 & 16.2 & 20.2 & 30.8 & 29.4 & 21.7 \\
\hline SD & 1.4 & 1.2 & 1.0 & 0.9 & 1.2 & 3.3 & 2.7 & 1.4 \\
\hline \multicolumn{9}{|c|}{ 21-d withdrawal } \\
\hline 9 & 15.3 & 14.6 & 14.6 & 12.2 & 17.6 & 28.4 & 23.6 & 19.7 \\
\hline 10 & 14.4 & 14.3 & 13.8 & 12.1 & 17.5 & 31.3 & 24.9 & 17.2 \\
\hline 11 & 17.0 & 16.6 & 15.9 & 13.6 & 18.5 & 27.0 & 26.1 & 20.1 \\
\hline 14 & 14.1 & 14.0 & 13.6 & 12.8 & 15.5 & 21.6 & 21.0 & 15.7 \\
\hline 15 & 14.4 & 14.1 & 13.6 & 12.2 & 15.7 & 27.0 & 22.7 & 15.7 \\
\hline Mean & 15.1 & 14.7 & 14.3 & 12.6 & 17.0 & 27.0 & 23.7 & 17.7 \\
\hline SD & 1.2 & 1.1 & 1.0 & 0.6 & 1.3 & 3.5 & 2.0 & 2.1 \\
\hline
\end{tabular}

with those of the 10-d group ( $P<0.01$, except for thalamus), returning to the level in nonsmokers ( $V t$ values did not show any significant difference compared with those in the nonsmokers). Figure 2 shows the percentage of reduction and increment in each group of smokers in comparison with the nonsmoker group. In the Tukey-Kramer multiple comparison test, the interval changes of the ${ }^{123}$ I-5IA $V t$ between the 3 phases after the smoking cessation were significantly different $(P<0.001)$.

The rate constant $K_{1}$ had some fluctuations among the different groups of volunteers (nonsmokers and smokers); however, these differences were not statistically significant (ANOVA; not significant) (Fig. 3A). On the other hand, the values of the rate constant $k_{2}$ were significantly different among the groups of volunteers (ANOVA; $P<0.01$ ) (Fig. 3B). This difference was due basically to the increase of $k_{2}$ in the group with $4 \mathrm{~h}$ of smoking cessation.

\section{DISCUSSION}

The present study described the effect of nicotine intake in tobacco smokers and smoking cessation on the high-affinity nicotinic receptors in humans using ${ }^{123}$ I-5IA SPECT. To our knowledge, this is the first in vivo imaging of nAChR upregulation and recovery in response to short-term smoking cessation in living smokers.

Previous animal studies have shown that chronic nicotine treatment induces an increase in high-affinity nicotinic receptor binding (6-9), and human postmortem studies have found a similar increase in ${ }^{3} \mathrm{H}$-nicotine binding to high-affinity receptors in the postmortem cortex, cerebellum, and hippocampus of smokers compared with that in nonsmokers (10-12).

The mechanism by which the chronic exposure of nicotine evokes an increase in the density of the binding sites is not fully understood. Marks et al. reported that the increase in nicotinic receptor numbers in rodents is not caused by an 


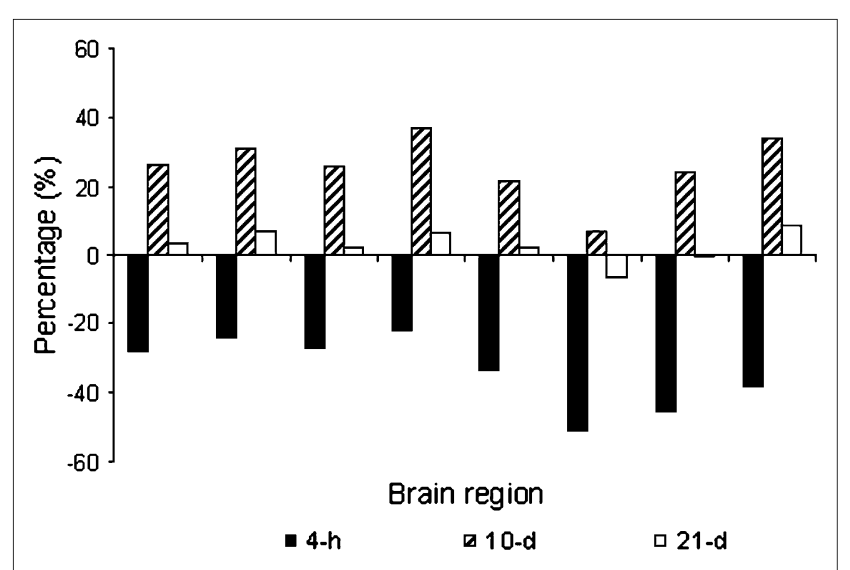

FIGURE 2. Percentage of reduction and increment of $V t$ of 123I-5IA in smokers after smoking cessation compared with nonsmokers. Eight brain regions are frontal, parietal, temporal, occipital, basal ganglia, thalamus, brain stem, and cerebellum from the left, respectively.

increase in messenger RNA levels (20). The lack of an effect on nicotinic receptor transcription in mice suggests that nicotine-induced increases in nicotinic receptor levels are most likely related to a decrease in receptor turnover (21). The increase in nicotinic receptor number and the decreased rate of receptor turnover may be related to nicotinic receptor channel desensitization, which appears to reflect the conformational state of the receptor channel $(21,22)$. Once the nicotinic receptor channels are desensitized and rendered inactive, additional receptors would be recruited to maintain the nicotinic response of the neuron, which results in an overall increase in nicotine binding, possibly due to a conversion of low-affinity receptors to a conformation with a high affinity for agonists (23).

In this study, the ${ }^{123}$ I-5IA $V t$ measured at $4 \mathrm{~h}$ after smoking cessation was significantly lower than that in nonsmokers. The mean value of the calculated $V t$ of the smokers was $\sim 33.5 \% \pm 10.5 \%$ lower than that of nonsmokers and was more pronounced in the thalamus $(51 \%)$ and brain stem $(45 \%)$. In this group of volunteers, the plasma nicotine level $4 \mathrm{~h}$ after smoking cessation was detectable in only 2 subjects and was below the detection limit in the other subjects. Nicotine is highly lipophilic and demonstrated high levels of nonspecific uptake in brain $(24,25)$. Rowell and $\mathrm{Li}$ have reported that levels of nicotine in the brain were $\sim 3$-fold higher than those in the plasma (7), which explains the lack of plasma nicotine measurements in 3 subjects in this group of volunteers. Because of high levels of nonspecific uptake of nicotine in the brain, nicotine or its metabolites may accumulate in nonspecific compartments in the brain (i.e., white matter) and then diffuse slowly into areas with higher levels of nAChRs, maintaining high levels of occupancy of the nAChRs. In addition, Brody et al. have shown saturation of the nicotinic receptors in human brain for up to $4 \mathrm{~h}$ in smokers (26). Thus, we would expect some level of nicotine or metabolites in the brain that would compete with ${ }^{123}$ I-5IA and impair imaging of the upregulation of nAChRs. Also, we believe that some level of nicotine in the brain resulted in a high level of occupancy of the receptors, which reduced specific tracer uptake (27). Because of competitive binding between the radioligand and nicotine in the brain, imaging of upregulation of nAChRs in vivo requires sufficient time for nicotine clearance ( $>4$-h smoking cessation).

After $10 \mathrm{~d}$ of smoking cessation, the $V t$ of ${ }^{123}$ I-5IA was significantly higher than that in nonsmokers, with a $25.7 \% \pm$ $9.2 \%$ increase among brain regions. The result of the increased $V t$ of the ${ }^{123}$ I-5IA was in agreement with the upregulation of the $\mathrm{nAChRs}$ in the brains of smokers reported in postmortem human studies (10-12) and in animal studies (6$9)$. Staley et al. have described similar findings in human brain (13). The authors noted that after $6.8 \pm 1.9 \mathrm{~d}$ of tobacco abstinence, the uptake of ${ }^{123}$ I-5IA increased significantly throughout the cerebral cortex (26\% 36\%) in smokers (13). After $10 \mathrm{~d}$ of smoking cessation, nicotine and cotinine were not detected in the plasma. Thus, blood nicotine levels were negligible in the ${ }^{123}$ I-5IA SPECT scans of smokers as well as nonsmokers.

After $21 \mathrm{~d}$ of smoking cessation, the $V t$ of ${ }^{123}$ I-5IA was significantly lower compared with that after $10 \mathrm{~d}$ of smoking cessation and was not significantly different from that in the nonsmokers. Breese et al. showed that smokers who had quit at least 2 mo before death had nicotinic receptor binding levels similar to those in nonsmokers (14). In the present study, the interval of $21 \mathrm{~d}$ was thought to be the recovery time during which upregulated $n A C h R s$ return to the level of the nonsmoker. This suggests that nicotineinduced upregulation of receptor number is a temporary effect, similar to that found in rodents $(28,29)$.

The upregulation of the nAChRs was similar in almost all brain regions, except the thalamus and basal ganglia, which showed a slightly different pattern. In thalamus and basal ganglia, after $10 \mathrm{~d}$ of smoking cessation the $V t$ was higher than that of the nonsmokers, as in the other regions, but was not significantly different. Staley et al. have shown similar findings (13). In addition, it has been reported in a study of mice that nicotine-induced increases in nicotinic receptor numbers do not increase to the same degree in all brain regions (30). Moreover, the nicotinic receptor is more abundant in the thalamus, with greater receptor heterogeneity, than in other brain regions (19). However, the characteristics of the acute response of neuronal $\mathrm{nAChRs}$ to nicotine depend on their subunit composition $(31,32)$. Nicotinic receptor subtypes are affected differentially by chronic exposure to nicotine, both in cell models (33-35) and in vivo (35). Multiple factors are thought to be responsible for these differences.

This study should be interpreted in the context of several limitations. (a) The number of subjects evaluated was small, which reduced the statistical accuracy. (b) The study design used did not allow us to deal with a within-subject analysis of the whole group, as the variables were analyzed independently. (c) The smokers varied in their rate and depth of inhalation of smoke, and these interindividual 
FIGURE 3. Temporal changes in rate constants $K_{1}$ and $k_{2}$ in nonsmokers and smokers after smoking cessation. (A) Rate constant $K_{1}(\mathrm{~mL} / \mathrm{g} / \mathrm{min})$. (B) Rate constant $k_{2}\left(\min ^{-1}\right)$. BG = basal ganglia; $\mathrm{BS}=$ brain stem.

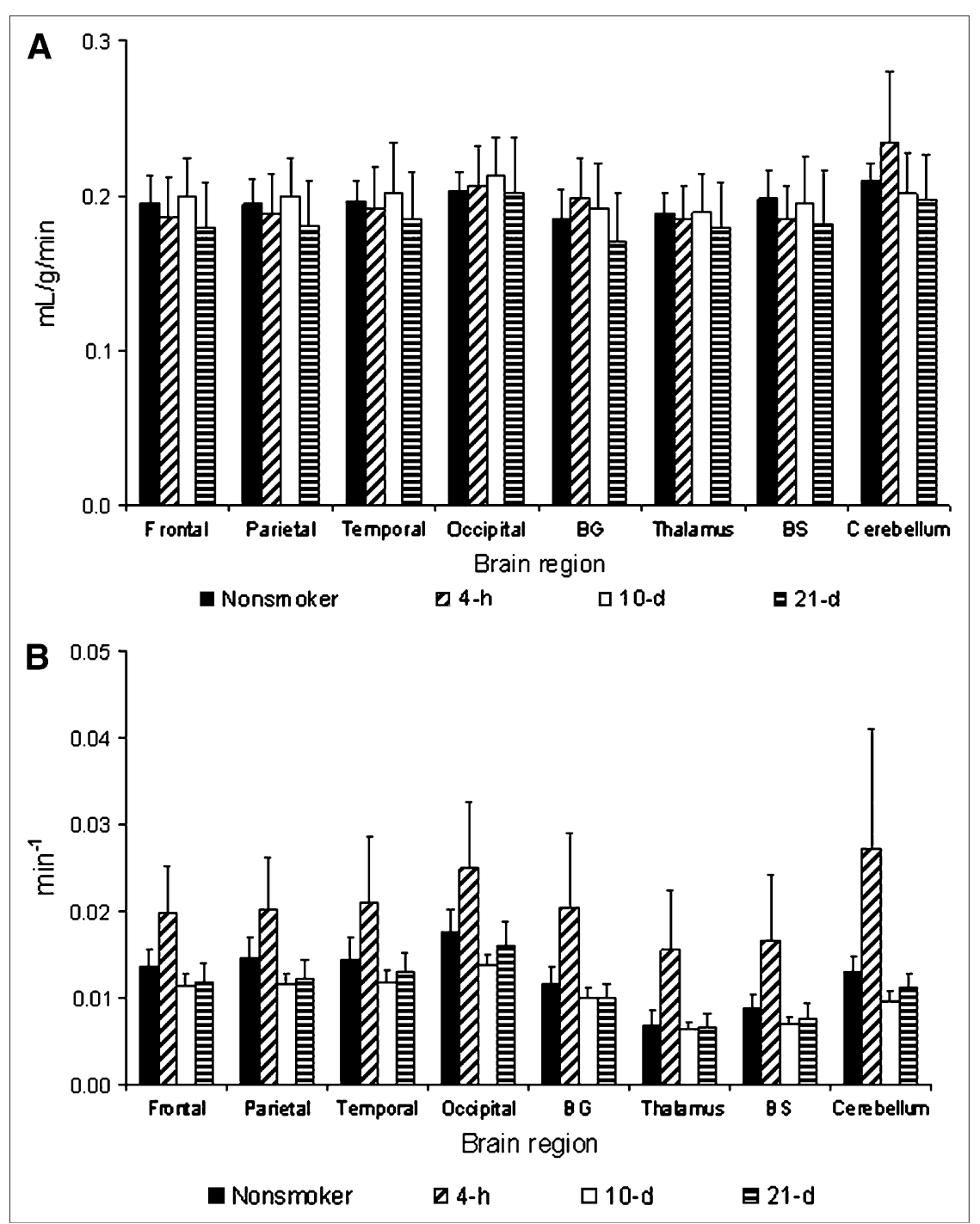

differences could have affected our measurements. (d) The detection limit of the plasma nicotine measurements was not enough to evaluate all blood samples. Thus, we were not able to correlate the plasma nicotine/cotinine levels with Vt. (e) We have not coregistered SPECT images with MRI, which would have been the most appropriate method for placement of ROIs. (f) We have not evaluated the smoker's behavior during the smoking-cessation period. We believe that the nicotine binding and desensitization of the nAChRs in the brain alleviate the cigarette craving and that craving will be the worst during the first $10 \mathrm{~d}$ of cessation due to the upregulation of nAChRs. The craving process should minimize after $21 \mathrm{~d}$, as we observe similar levels of occupancy as nonsmokers at that time. However, we cannot exclude the possibility of other nAChR subtypes being involved in the process of tobacco dependence.

\section{CONCLUSION}

We have described the in vivo imaging of nAChR upregulation and recovery in response to short-term smoking cessation in smokers using ${ }^{123}$ I-5IA SPECT. Our results clearly suggest that tobacco smoking is associated with an upregulation of nicotine binding sites in the brain. The upregulation of the nAChRs of the smokers after chronic exposure to nicotine was downregulated to the level in nonsmokers after $\sim 21 \mathrm{~d}$ of smoking cessation. Thus, the upregulation of receptor numbers is a temporary effect. Nicotine dependence and difficulty in smoking cessation are also interesting with regard to the findings of the ${ }^{123}$ I-5IA SPECT study. The decrease in nicotinic receptors to nonsmoker levels may be the breaking point during the nicotine withdrawal period.

\section{ACKNOWLEDGMENTS}

The authors thank Dr. Masanori Ichise (Department of Radiology, Columbia University, College of Physicians and Surgeons) for his tremendous editorial support and suggestions on this project. The authors also thank Nihon MediPhysics Co. Ltd., Japan, for providing sodium ${ }^{123}$ I-iodide. 
This work was supported in part by a grant from the Research for the Future Program of the Japan Society for the Promotion of Science (JSPS-RFTF97K00201); Grants-in-Aid for Scientific Research from the Ministry of Education, Science and Technology of Japan; a research grant from Longevity Sciences from the Ministry of Health and Welfare; and a grant from the Smoking Research Foundation.

\section{REFERENCES}

1. Gotti C, Fornasari D, Clementi F. Human neuronal nicotinic receptors. Prog Neurobiol. 1997;53:199-237.

2. Paterson D, Nordberg A. Neuronal nicotinic receptors in the human brain. Proc Neurobiol. 2000;61:75-111.

3. Shimohama S, Kihara T. Nicotinic receptor-mediated protection against betaamyloid neurotoxicity. Biol Psychiatry. 2001;49:233-239.

4. Decker MW, Rueter LE, Bitner RS. Nicotinic acetylcholine receptor agonists: a potential new class of analgesics. Curr Top Med Chem. 2004;4:369-384.

5. Buisson B, Bertrand D. Nicotine addiction: the possible role of functional upregulation. Trends Pharmacol Sci. 2002;23:130-136.

6. Pietila K, Lahde T, Attila M, Ahtee L, Nordberg A. Regulation of nicotinic receptors in the brain of mice withdrawn from chronic oral nicotine treatment. Naunyn Schmiedebergs Arch Pharmacol. 1998;357:176-182.

7. Rowell PP, Li M. Dose-response relationship for nicotine-induced up-regulation of rat brain nicotinic receptors. J Neurochem. 1997;68:1982-1989.

8. Collins AC, Romm E, Wehner JM. Dissociation of the apparent relationship between nicotine tolerance and up-regulation of nicotinic receptors. Brain Res Bull. 1990;25:373-379.

9. Koylu E, Demirgoren S, London ED, Pogun S. Sex difference in up-regulation of nicotinic acetylcholine receptors in rat brain. Life Sci. 1997;61:L185-L190.

10. Perry DC, Davila-Garcia MI, Stockmeier CA, Kellar KJ. Increased nicotinic receptors in brains from smokers: membrane binding and autoradiography studies. J Pharmacol Exp Ther. 1999;289:1545-1552.

11. Teaktong T, Graham AJ, Johnson M, Court JA, Perry EK. Selective changes in nicotinic acetylcholine receptor subtypes related to tobacco smoking: an immunohistochemical study. Neuropathol Appl Neurobiol. 2004;30:243-254.

12. Kassiou M, Eberl S, Meikle SR, et al. In vivo imaging of nicotinic receptor upregulation following chronic (-)-nicotine treatment in baboon using SPECT. Nucl Med Biol. 2001;28:165-175.

13. Staley JK, Krishnan-Sarin S, Cosgrove KP, et al. Human tobacco smokers in early abstinence have higher of $\mathrm{b} 2 *$ nicotinic acetylcholine receptors than nonsmokers. J Neurosci. 2006;26:8707-8714.

14. Breese CR, Marks MJ, Logel MJ, et al. Effect of smoking history on $\left[{ }^{3} \mathrm{H}\right]$ nicotine binding in human postmortem brain. J Pharmacol Exp Ther. 1997; 282:7-13.

15. Saji H, Ogawa M, Ueda M, et al. Evaluation of radioiodinated 5-iodo-3-(2(S)azetidinylmethoxy)pyridine as a ligand for SPECT investigations of brain nicotinic acetylcholine receptors. Ann Nucl Med. 2002;16:189-200.

16. Musachio JL, Scheffel U, Finley PA, et al. 5-[I-125/123]Iodo-3(2(S)-azetidinylmethoxy)pyridine, a radioiodinated analog of A-85380 for in vivo studies of central nicotinic acetylcholine receptors. Life Sci. 1998;62:351-357.
17. Ueda M, Iida Y, Mukai T, et al. 5-[ $\left.{ }^{123} \mathrm{I}\right]$ Iodo-A-85380: assessment of pharmacological safety, radiation dosimetry and SPECT imaging of brain nicotinic receptors in healthy human subjects. Ann Nucl Med. 2004;18: 337-344.

18. Vaupel DB, Tella SR, Huso DL, et al. Pharmacology, toxicology, and radiation dosimetry evaluation of [I-123]5-I-a-85380, a radioligand for in vivo imaging of cerebral neuronal nicotinic acetylcholine receptors in humans. Drug Dev Res. 2003;58:149-168.

19. Mamede M, Ishizu K, Ueda M, et al. Quantification of human nicotinic acetylcholine receptors with ${ }^{123}$ I-5IA SPECT. J Nucl Med. 2004;45:1458-1470.

20. Marks MJ, Pauly JR, Gross SD, et al. Nicotine binding and nicotinic receptor subunit RNA after chronic nicotine treatment. J Neurosci. 1992;12:2765-2784.

21. Peng X, Gerzanich V, Anand R, Whiting PJ, Lindstrom J. Nicotine-induced increase in neuronal nicotinic receptors results from a decrease in the rate of receptor turnover. Mol Pharmacol. 1994;46:523-530.

22. Marks MJ, Burch JB, Collins AC. Genetics of nicotine response in four inbred strains of mice. J Pharmacol Exp Ther. 1983;226:291-302.

23. Bencherif M, Fowler K, Lukas RJ, Lippiello PM. Mechanisms of up-regulation of neuronal nicotinic acetylcholine receptors in clonal cell lines and primary cultures of fetal rat brain. J Pharmacol Exp Ther. 1995;275:987-994.

24. Broussolle EP, Wong DF, Fanelli FJ, London ED. In vivo specific binding of $\left[{ }^{3} \mathrm{H}\right] 1$-nicotine in the mouse brain. Life Sci. 1989;44:1123-1132.

25. Muzic R, Berridge M, Friedland R, Zhu N, Nelson A. PET quantification of specific binding of carbon-11-nicotine in human brain. J Nucl Med. 1998;39: 2048-2054.

26. Brody AL, Mandelkern MA, London ED, et al. Cigarette smoking saturates brain $\alpha 4 \beta 2$ nicotinic acetylcholine receptors. Arch Gen Psychiatry. 2006;63: 907-915.

27. Ding Y-S, Volkow ND, Logan J, et al. Occupancy of brain nicotinic acetylcholine receptors by nicotine doses equivalent to those obtained when smoking a cigarette. Synapse. 2000;35:234-237.

28. Collins AC, Bhat RV, Pauly JR, Marks MJ. Modulation of nicotine receptors by chronic exposure to nicotinic agonists and antagonists. Ciba Found Symp. 1990; 152:68-82.

29. Marks MJ, Stitzel JA, Collins AC. Time course study of the effects of chronic nicotine infusion on drug response and brain receptors. J Pharmacol Exp Ther. 1985;235:619-628.

30. Collins AC, Marks MJ, Pauly JR. Differential effect of chronic nicotine treatment on nicotinic receptor numbers in various brain regions of mice. J Subst Abuse. 1989;1:273-286.

31. Luetje CW, Patrick J. Both $\alpha$ and $\beta$ subunits contribute to the agonist sensitivity of neuronal acetylcholine receptors. J Neurosci. 1991;11:837-845.

32. Fenster CP, Rains MF, Noerager B, Quick MW, Lester RAJ. Influence of subunit composition on desensitization of neuronal acetylcholine receptors at low concentrations of nicotine. J Neurosci. 1997; 17:5747-5759.

33. Hsu Y-N, Amin J, Weiss DS, Wecker L. Sustained nicotine exposure differentially affects $\alpha 3 \beta 2$ and $\alpha 4 \beta 2$ neuronal nicotinic receptors expressed in Xenopus oocytes. J Neurochem. 1996;66:667-675.

34. Olale F, Gerznich V, Kurytov A, Wang F, Lindstrom J. Chronic nicotine exposure differentially affects the function of human $\alpha 3, \alpha 4$ and $\alpha 7$ neuronal nicotinic receptor subtypes. J Pharmacol Exp Ther. 1997;283:675-683.

35. Peng X, Gerzanich V, Anand R, Wang F, Lindstrom J. Chronic nicotine treatment up-regulates $\alpha 3$ and $\alpha 7$ acetylcholine receptor subtypes expressed by the human neuroblastoma cell line SH-SY5Y. Mol Pharmacol. 1997;51:776-784. 